\title{
INFLUENCE OF THE PLOTS FORMAT ON THE PERFORMANCE INDEX OF THE SOYBEAN COMBINE HARVESTER
}

Doi:http://dx.doi.org/10.1590/1809-4430-Eng.Agric.v37n5p961-972/2017

\section{CARLA S. S. PAIXÃO ${ }^{1}$, MURILO A. VOLTARELLI ${ }^{2 *}$, ROUVERSON P. DA SILVA ${ }^{1}$, TIAGO DE O. TAVARES ${ }^{1}$, LUCAS A. DA S. GÍRIO ${ }^{1}$}

\author{
$2^{2 *}$ Corresponding author. Federal University of São Carlos - Lagoa do Sino/ Buri - SP, Brazil.
}

E-mail: voltarelli@ufscar.br

\begin{abstract}
The intensive mechanization during the harvest operation and success of this operation depends on several factors, one of which is the length and format of the plots. The aim of this study was to evaluate the operating performance of a soybean harvester in different geometric plots shape, using as quality indicators performance parameters by means of statistical control tools of process. The experiment was conducted in March 2014 in the city of Uberaba - MG. Operational capacity was evaluated in the mechanical harvesting of soybeans in three plots: irregular, rectangular and trapezoidal. Performance evaluations of soybean harvester were made from the following parameters: displacement speed, engine rotation, cylinder rotation and concave opening. The grain water contents affect the quality indicators of the soybean harvester performance in all plots shapes. The harvester performance is considered able to maintain between the specification limits and close to the target, to speed quality indicators the irregular and the trapezoidal plots and for cylinder rotation the trapezoidal plot.
\end{abstract}

KEYWORDS: Control charts, Grain harvester, Quality control, Glycine max (L.) Merrill.

\section{INTRODUCTION}

Information on soybean mechanized harvesting can indicate actions that can reduce its cost and, consequently, increase the profitability of the crops. Correct harvesting planning, especially by means of a suitable sizing of the harvester, avoids its underutilization (Chioderoli et al., 2012). However, in order to carry out the sizing adequately, it is necessary to know the information about the considered parameters of the operational performance, according to the conditions in which the harvesters will operate (Araldi et al., 2013).

Success in mechanized harvesting depends on several factors, and one of the major influences is the length and shape of the plots. This, combined with the minimization of crop losses, increases productivity. Associated to this, the speed of the windlass, the trellis cylinder rotation, the opening between the cylinder and the concave, and the speed of work are among the main factors that interfere in the losses of soybean mechanized harvest. In relation to the factors linked to the losses of grains not originating from the mechanized harvest process it can be mention the dehiscence of the pods, inadequate sowing, the wrong choice of the cultivar, the occurrence of weeds, and the bad development of the crop (Compagnon et al., 2012; Srivastava et al., 1993).

The operational performance of the machines can also be influenced by the operator, through the necessary hours for feeding (snacks and water), rest and personal hygiene, as well as the time of experience and the state of the worker anxiety. The impediments present in the field, the working speed of the harvester and the need for technical stops for maintenance and repairs are also factors that can influence the operational performance during harvesting (Linhares et al., 2012).

Chioderoli et al. (2012) when determining the quantitative losses during harvesting in soybean crop observed that the harvesting operation quality and the harvester settings were dependent on the speed of the machine. According to Aguila et al. (2011), the highest percentage of losses may be related to the poor regulation of the machine, especially in the cutting and feeding mechanism, reaching values from 80 to $85 \%$ of the total losses.

\footnotetext{
${ }^{1}$ São Paulo State University (Unesp), School of Agricultural and Veterinarian Sciences/ Jaboticabal - SP, Brazil. 
Quality control is perfectly adaptable to the agricultural production system, but the use of Statistical Process Control (SPC) for continuous monitoring, detection and elimination of variation sources, and finally improvement of the process as a whole keep it stable (Voltarelli et al., 2013). The use of statistical process control to evaluate and / or monitor quality indicators from mechanized agricultural operations is still incipient in Brazil, but it is possible to find studies with applications of these tools using the control charts in the mechanized harvest of beans (Silva et al., 2013) and coffee (Cassia et al., 2013; Custodio et al., 2012) and mechanized sowing of peanuts (Zerbato et al., 2014).

Based on the assumption that the performance of the mechanized soybean harvesting operation can be influenced by the geometric shape of the plots in which the crop was planted, this study aim was to evaluate the operational performance of a soybean harvester in different geometric formats of the plots by means of statistical process control tools.

\section{MATERIAL AND METHODS}

The experiment was carried out in March 2014, in the municipality of Uberaba - MG, in an area of the São Sebastião farm located near the geodesic coordinates: Latitude: 1944'54"S, Longitude: $47^{\circ} 55^{\prime} 55^{\prime \prime} \mathrm{W}$ with average altitude of 801 and weather Aw according to Köppen's classification. Three plots with different geometric shapes were evaluated in the same area being characterized in Table 1.

TABLE1. Average dimensional characteristics of geometric shapes plots evaluated for mechanized harvesting soybeans.

\begin{tabular}{lccc}
\hline Characteristics & Irregular & Rectangular & Trapezoidal \\
\hline Area (ha) & 4.41 & 8.36 & 7.19 \\
Length $(\mathrm{m})$ & 448 & 1,159 & 1,136 \\
Width $(\mathrm{m})$ & 85 & 84 & 90 \\
Water content of the grains $(\%)$ & 11.70 & 12.50 & 15.11 \\
\hline
\end{tabular}

Seeding was carried out for soybean crop in November 2013, using the BMX Turbo RR variety developed by BRASMAX, spaced $0.50 \mathrm{~m}$ between rows and 21 seeds $\mathrm{m}^{-1}$, totaling a mean population of approximately 420,000 plants $\mathrm{ha}^{-1}$.

A harvester of brand Massey Ferguson, model MF 5650 Advanced year 2010 for soybean mechanized harvesting was used in approximately $700 \mathrm{~h}$ of work. The harvester features AGCO Sisu Power six-cylinder engine, with nominal power of $130 \mathrm{~kW}$ (175 hp); equipped with a cutting platform $5.00 \mathrm{~m}$ wide; tangential type track system; separating by straws-bulk, and tank with capacity of 5,500 L.

The samples were collected according to the assumptions of the static quality control being determined between a fixed interval of time (15 minutes) for the evaluations, being 18, 28 and 24 repetitions for the irregular, rectangular and trapezoidal plots, respectively. The treatments were established from the geometric formats of the plots, without the need to change the operator of the harvester during harvest, thus providing better control conditions for the experiment.

The performance evaluations of the soybean harvester were done from the following parameters: working speed, engine rotation, cylinder rotation and concave opening being all variables collected through the front column monitor found inside the harvester's cab. These variables were collected by an evaluator inside the harvester's booth, in which was recorded the sample points from the frontal column monitor at the predetermined time. The characterization of water content of the grains was carried out by means of a digital meter model G600, collecting 20 samples in the harvest period for each plot. It should also be pointed out that the harvested area in the three plots formats had low weed infestation. 
The control charts model selected was the exponentially weighted moving average (EWMA) since it represents the individual observations, and the analysis is more rigorous, it is assumed that it demonstrates better the process variation in these cases (Montgomery, 2009). The control charts model in which it is used the exponentially weighted moving average (EWMA), also referred to as advanced control charts, are enhancements of the Shewhart charts, which were developed for specific situations when it is desired to simultaneously minimize the occurrence of points outside the control limits (false alarms) and non-visible alarms, due to their greater rigor of analysis (Montogomery, 2009).

The exponentially weighted moving average (EWMA) is defined according to Montgomery (2009) according to [eq. (1)]:

$$
z_{i}=\lambda \cdot \sum_{j=0}^{i-1}(1-\lambda)^{j} \cdot x_{i-j}+(1-\lambda)^{i} \cdot z_{0}
$$

where,

$z_{i}:$ Value of the Weighted Moving Average;

$x_{i:}$ Value of the measured characteristic;

$z_{0}:$ Target average of the process;

$\lambda$ : Stiffness factor of the analysis, and

$i: 1,2,3$, (samples).

The upper and lower control limits of the charts that make up the exponentially weighted moving average (EWMA) are calculated as a function of eqs (2) and (3), respectively:

$$
\begin{aligned}
& \text { UCL }=\mu+\text { L. } \sigma \cdot \sqrt{\frac{1}{(2-\lambda)} \cdot\left[1-(1-\lambda)^{2 \mathrm{i}}\right]} \\
& \text { LCL }=\mu-\text { L. } \sigma \cdot \sqrt{\frac{1}{(2-\lambda)} \cdot\left[1-(1-\lambda)^{2 \mathrm{i}}\right]}
\end{aligned}
$$

where,

UCL: Upper limit of control;

LCL: Lower limit of control;

$\mu$ : Overall average;

L: Width of the range between the mean and the limit;

$\sigma:$ Standard deviation;

$\lambda$ : Stiffness factor of the analysis,

i: $1,2,3$, (samples).

The exponentially weighted moving average control charts were calculated using the bandwidth between the average and the control limits, as the value 3 (three) and the stiffness factor of the analysis was chosen $\lambda=0.4$. These values were chosen based on the recommendation by Montgomery $(2009)$ and Hunter $(1986 ; 1989)$ in which the authors recommend to use $(\lambda=0.4)$ when using bandwidth with value 3 (three). It is also worth noting that such tool does not require the normal distribution of probability of the data to be used in the monitoring processes. 
However, such recommendations are based on the analysis of industrial production items, where the variations are minimal between the items and / or produced pieces. The choice of value $(\lambda$ $=0.4$ ) was due to the fact that specific studies on the use of this value applied to agricultural quality indicators that have a high variation when compared to others are still scarce and / or absent for most agricultural mechanized operations.

In order to perform the process capability analysis and verify if it is able to produce conforming items over time, both in the short term and in the long term, it is necessary that it meets the following rules (MINITAB, 2007): the data set should show normal probability distribution (Rule 1); the control charts must present only common or natural variations with all points within the control limits (Rule 2).

This analysis is represented by a histogram used to verify the behavior of the data, in relation to the established standards, and by several capacity indices used to calculate the amount of defects or products outside the specifications that the process can produce, without and with the removal of causes not inherent to the process.

The specific or established limits also called engineering limits are parameters based on technical recommendations, agricultural criteria which can provide better quality standards for eventual process, and economic contained in bibliography or in usual values for evaluated quality indicators. The specific control limits (Table 2) were defined along with managers (supervisor and agricultural manager) of the operation, as well as with the other employees (operator of the harvester and transshipment) so that the operation had $90 \%$ of quality.

TABLE 2. Specific control limits used in soybean mechanized harvesting operation.

\begin{tabular}{lccc}
\hline \multirow{2}{*}{ Quality Indicators } & \multicolumn{2}{c}{ Specific limit } & \multirow{2}{*}{ Target } \\
\cline { 2 - 3 } & Lower (LSL) & Upper (USL) & \\
\hline Speed $\left(\mathrm{km} \mathrm{h}^{-1}\right)$ & 3.5 & 6.0 & 5.0 \\
Cylinder rotation $(\mathrm{rpm})$ & 1,000 & 1,100 & 1,050 \\
Engine rotation $(\mathrm{rpm})$ & 2,550 & 2,575 & 2,560 \\
Opening of the concave $(\mathrm{mm})$ & 20 & 40 & 30 \\
\hline
\end{tabular}

\section{RESULTS AND DISCUSSION}

The working speed of the soybean harvester showed stable behavior during the operation for the three geometric formats of the evaluated plots with all points within the lower and upper limit control (Figure 1). 


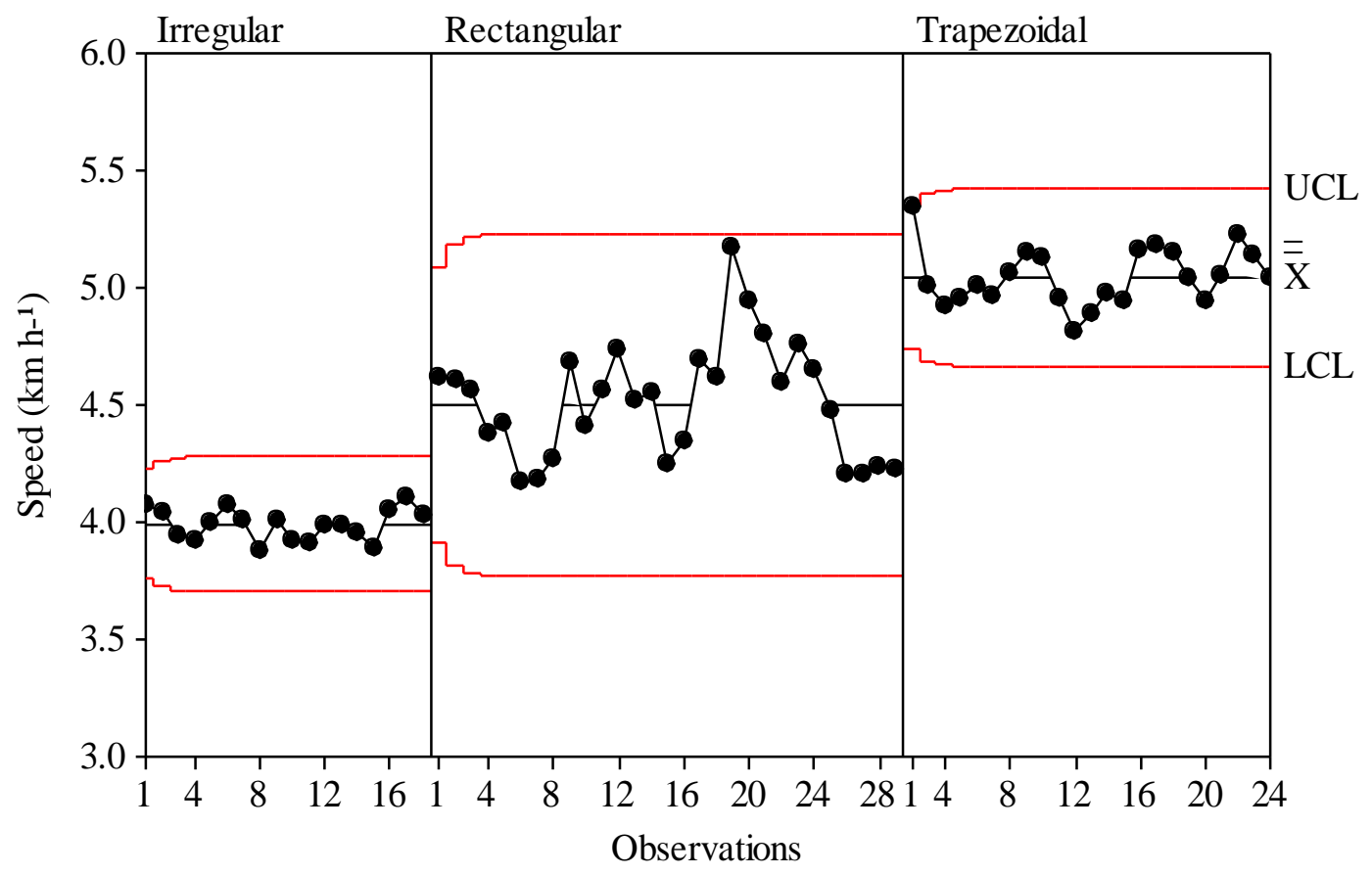

FIGURE 1. Control charts for the harvester working speed during soybean mechanical harvesting for different formats of plots.

On the other hand, it is observed that the lower variation of this quality indicator occurred in irregular shaped plot with the majority of the sampling points concentrating around a single value, which reflected in control limits close to the average, inverse situation to what happened in the rectangular plot. Therefore, Costa et al. (1996) state that the average speed most used in the soybean mechanical harvesting by harvesters has been around $4.5 \mathrm{~km} \mathrm{~h}^{-1}$ as observed in the present study.

In Figure 2 it is possible to observe that the quality indicator of cylinder rotation on soybean harvester presented similar behavior to the displacement speed being verified the stability of the process during the operation for the three plots formats with all points within the lower and upper control limits.

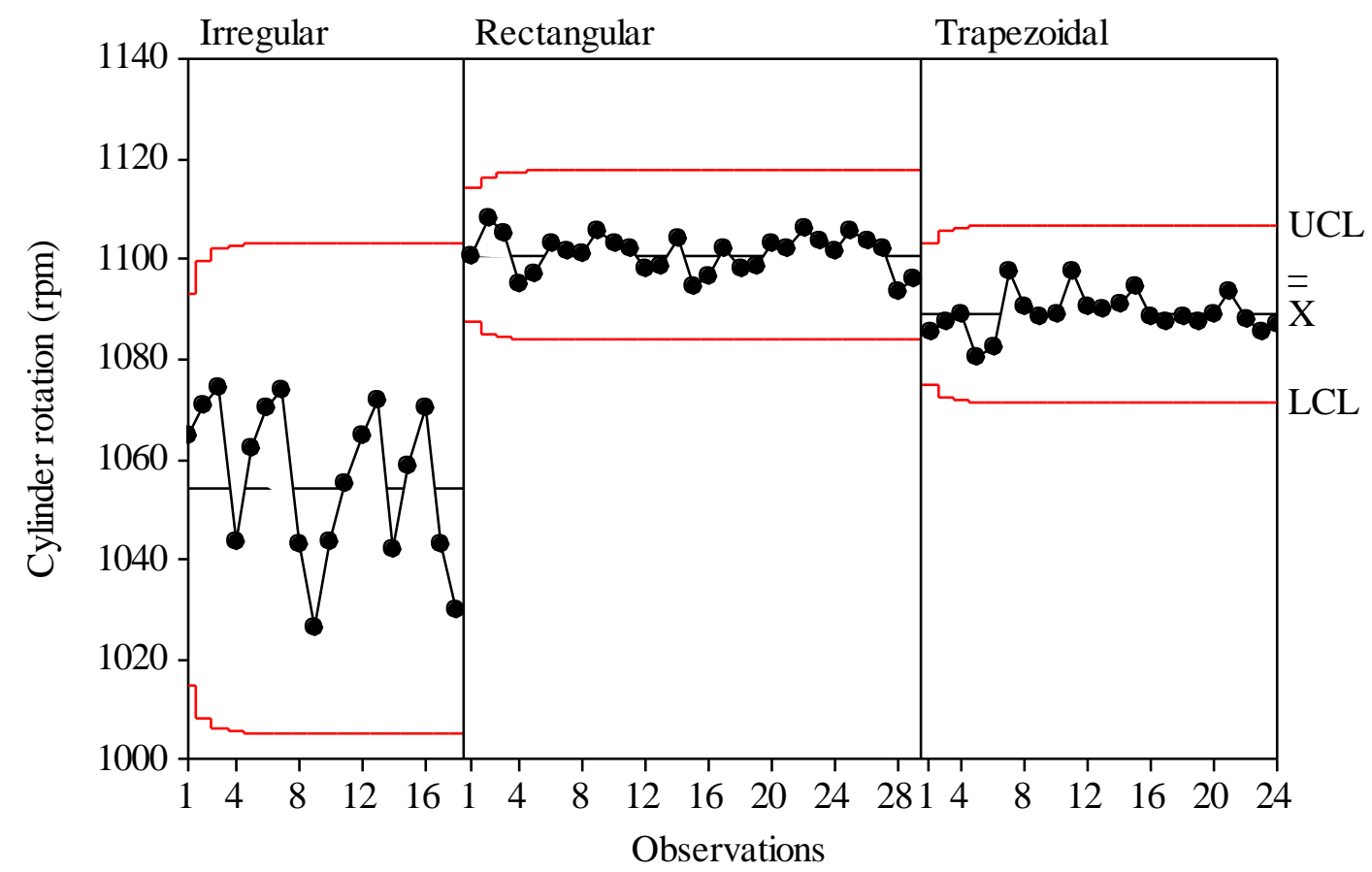

FIGURE 2. Control charts for the cylinder rotation of the harvester for soybean mechanized harvesting for different formats of plots. 
Note that the largest variation occurred in the irregularly shaped plot, and for the rectangular and trapezoidal plot the majority of the sample points were concentrated around a single value, which reflected near-average control limits. This is mainly due to the water content of the grains, because during harvesting of the irregular plot the grains were drier (water content of $11.75 \%$ ) and thus the cylinder rotation was smaller, whereas in the other plots the grains were more humid due to the rain that occurred in the period prior to harvesting (Table 1).

Mesquita et al. (2001) observed that during the soybean mechanized harvesting we must adopt a series of important factors to be considered, being: the basic regulation of the harvesters which involve cutting height of the platform, windlass speed, the trellis cylinder rotation, cylinder and concave opening, displacement speed of the harvester among others.

The speed of the soybean harvester engine showed unstable behavior during the harvesting operation (Figure 3), showing a point outside the lower control limit for the irregular (observation $\mathrm{n}^{\mathrm{o}}$ 5) and trapezoidal (observation $\mathrm{n}^{\circ}$ 8) plots. However, these points can be attributed to the fact that the interval between the established limits is smaller, and therefore these occurrences do not affect the performance of the machine during the harvest.

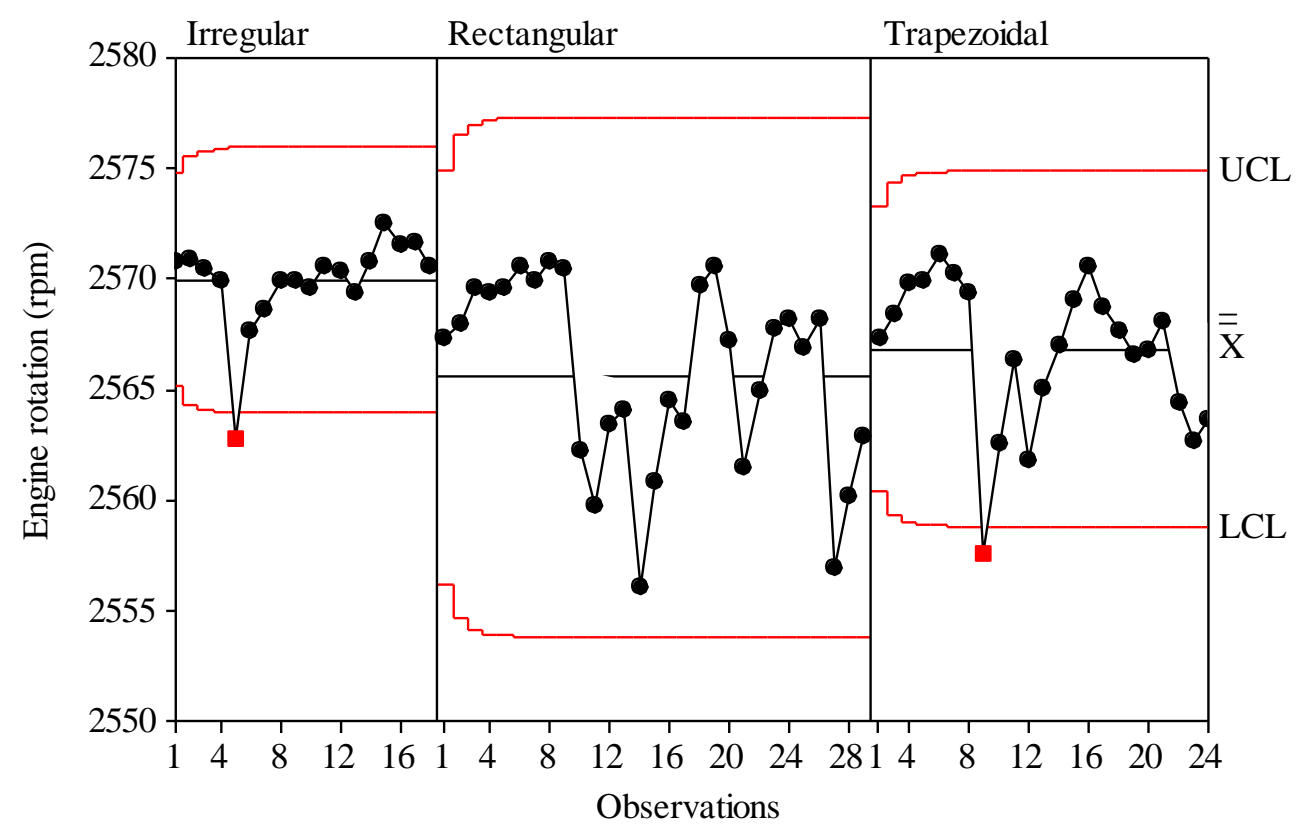

FIGURE 3. Control charts for the harvester engine rotation for soybean mechanized harvesting for different formats plots.

On the other hand, the rectangular plot proved to be stable throughout the harvesting process with all points within the lower and upper control limits, but a greater variation on the rotation values when compared to the irregular plot.

As reported by Chioderoli et al. (2012) grain losses in the soybean mechanized harvest presented instability on the process for the quality indicator motor rotation, a similar situation to that evidenced in the irregular and trapezoidal plots for the present study. It should be pointed out that, despite the processes being out of control, this did not damage the performance of the harvester during the operation.

The opening of the concave presented unstable behavior during the operation for three formats of the evaluated plots, with most points outside the lower and upper control limits (Figure 4). This can be explained by the fact that the calculated limits show values very close to each other, indicating the lowest variability during the harvest. 


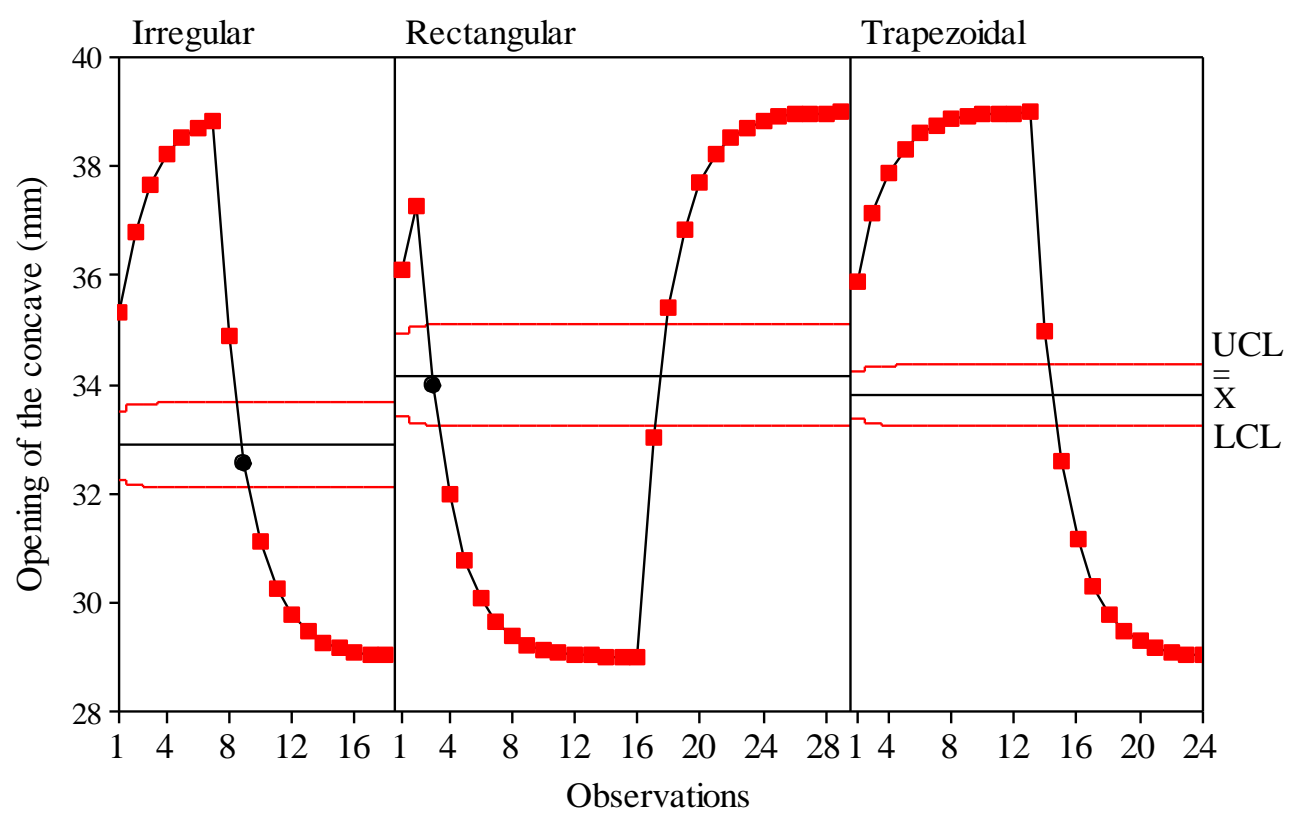

FIGURE 4. Control charts for the opening of the concave of the harvester for soybean mechanized harvesting for different formats of plots.

Adjusting the concave opening is directly linked to the water content of the grains, being established a range from 29 to $39 \mathrm{~mm}$, so that, when the grains were with lower water content, the greater the opening of the concave and vice-versa. Although the variable is out of control, potentially the process cannot be considered inefficient or detrimental to the harvest quality, since the variation was not expressive. It is also observed that in the irregular and trapezoidal plots as the grains were drier at the beginning of the harvest (Table 1), the highest values were found for the opening of the concave, and as the water content increased, this opening diminished in order to better tread the grains.

The quality indicators cylinder rotation in irregular and rectangular plots, the engine rotation and the opening of the concave in all evaluated plots (irregular, rectangular and trapezoidal) did not present the two basic premises for the analysis of the process ability, which are the normality and the stability of the process making this analysis impracticable because they do not represent certain reliability index. Also noted in the capacity graphs presented below, the abbreviations "potential $\mathrm{Dp}$ " and "General Dp" represent the potential standard deviation and the general standard deviation, respectively.

For the quality indicator working speed in the irregular plot there was considerable approximation of the potential and general distribution curves being evidenced by the proximity of the indexes $\mathrm{Cp}$ (potential capability index) and Pp (general capability index), however, the Pp is higher than $\mathrm{Cp}$, resulting in the potential production of satisfactory items produced over a longer period of time (Figure 5). 


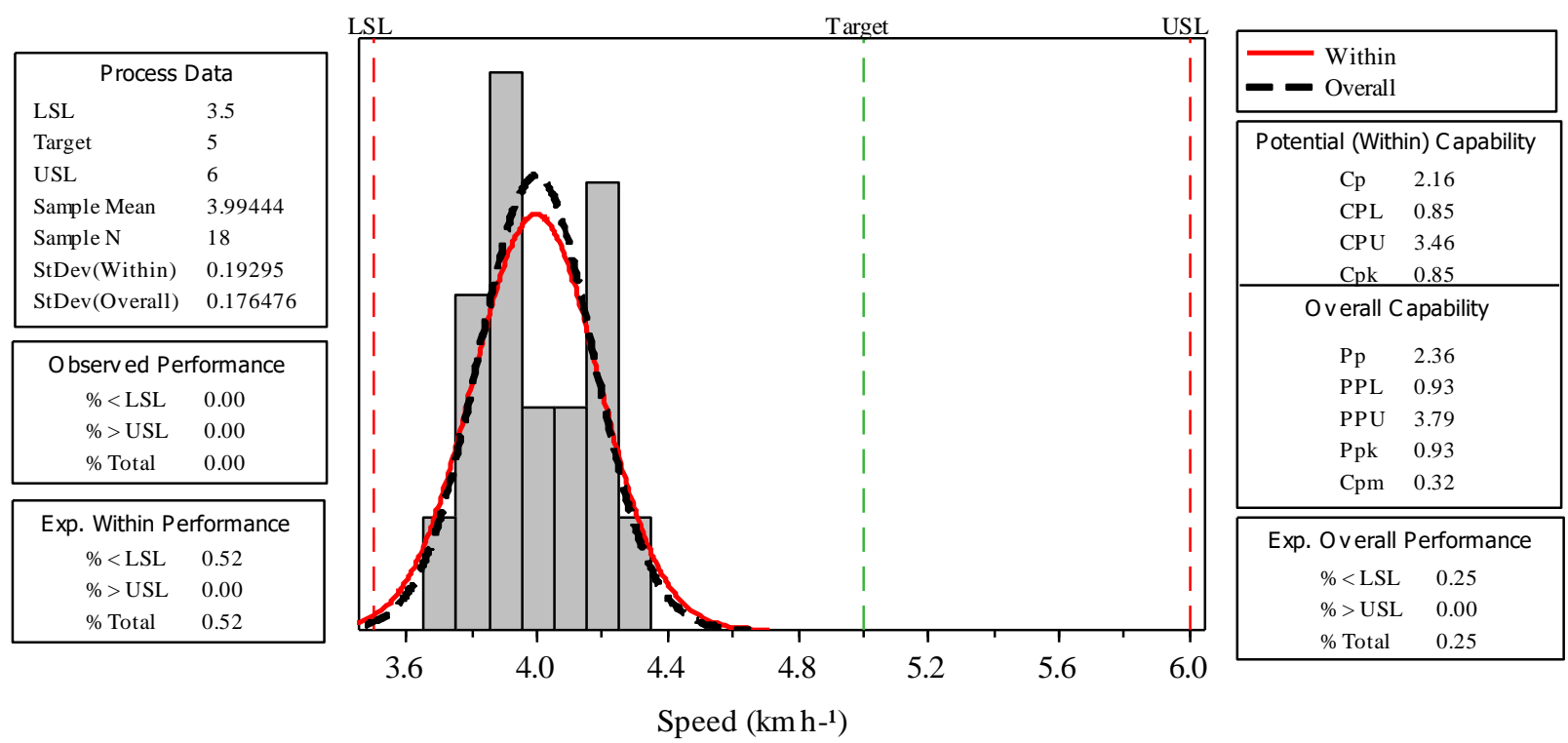

FIGURE 5. Analysis of the process capability for the working speed of the harvester in the irregular plot during the soybean mechanized harvesting.

It can also be observed from the current performance of the process that there was no production of items or observations outside the specified limits (SOL and SLL), portraying that the values meet the specifications limits. However, the capability indices $(\mathrm{Cp}=2.16$ and $\mathrm{Pp}=2.36)$ were higher than the stipulated minimum (1.33), so that the process is considered capable of producing results within the specific limits in the short and long term, respectively.

The indexes $\mathrm{Cp}$ and $\mathrm{Cpm}$ (2.16 and 0.32, respectively) can be considered separated from each other, however, the value of $\mathrm{Cpk}(0.85)$ is higher than $\mathrm{Cpm}$, confirming the decentralization of the whole process in relation to the established target, but the same is capable in the short and long term. This positive value $\mathrm{Cpk}$ is an indication that the general average (3.99) is within the specifications, i.e. between SLL and SUL.

Voltarelli et al. (2014) reported the analysis of the process capacity for the sugarcane mechanized planting as a function of the operating shifts that presented capacity index lower than the minimum required value (1.33) demonstrating the inability of the process to meet the specifications in both short and long term. In contrast to this situation, the evaluated operation in this study has the potential to reach the limits of specification in the short term and if improvements are made to further reduce the sources of extrinsic variability to the process, it may reach the demand in the long term what is essential for the management of this activity.

The velocity process capability in the rectangular plot, despite the proximity presented by the potential and general distribution curves, the process has a slight decentralization in relation to the specified target, and can also be observed by checking the proximity of the index Cp (0.85), Pp (0.86) and Cpm (0.48) (Figure 6). This fact portrays the process as being incapable of producing items in the short and long term due to the $\mathrm{Cp}$ and $\mathrm{Pp}$ indexes are less than 1.33 for both the potential and the general capacity index, respectively. 


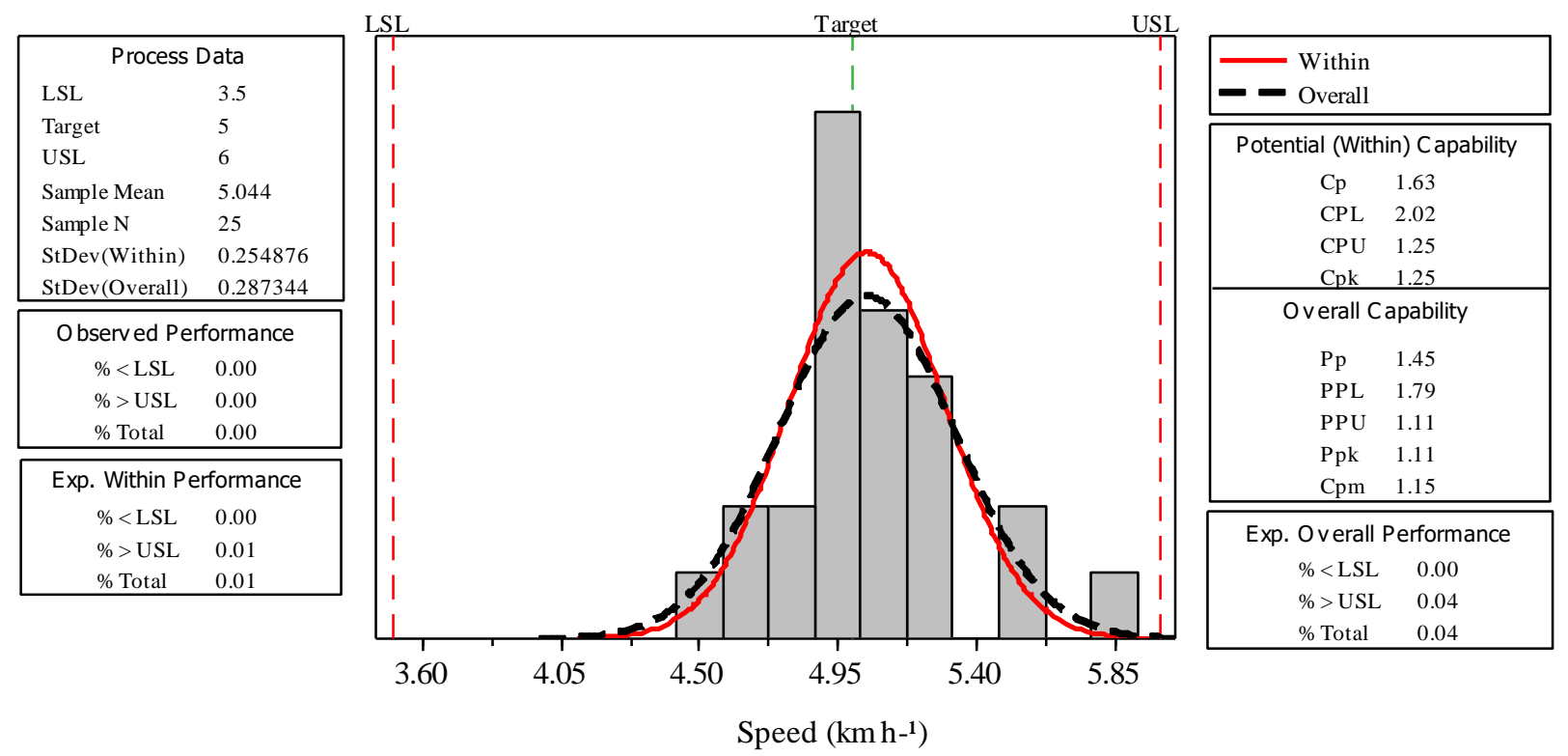

FIGURE 6. Analysis of the process capability for the speed of the harvester in the rectangular plot during the soybean mechanized harvest.

The low values of Cpk and Ppk may be indicative that the process is centralized, but there is variability occurring beyond the range of the specification limits, and can be demonstrated by the values of the general process performance in which there are $2.02 \%$ of the observations with special and random cause influences. This situation means that even if these values have a normal distribution and the process is stable there will be a variation between the sample values, i.e. it is impossible to reach the full capacity of the process, unless measures for screening, continuous monitoring and improvement of the operation were carried out as a whole.

Czarski \& Matusiewicz (2012) using statistical control techniques in association with measurement analysis system, also found the process as incapable of producing satisfactory items regardless of the centralization of the process in the target. The same authors also reported that, due to the high values $\mathrm{Cp}$ and $\mathrm{Cpk}$ (1.17 and 1.14, respectively), adjustment measures should be performed in order to the process become capable, as the one found for speed in the rectangular plot.

In the trapezoidal plot the capacity of the process as a function of the harvester speed movement was potentially able to meet the specification limits at short $(\mathrm{Cp}=1.63)$ and long term $(\mathrm{Pp}=1.45)$. However, the considerable approximation of the potential and general distribution curves can indicate that the process is centered on the target, being evidenced by the indexes Cpk (1.25), Ppk (1.11) and Cpm (1.15) with values close to each other which characterize the centralization of the process in relation to the established target (Figure 7). 

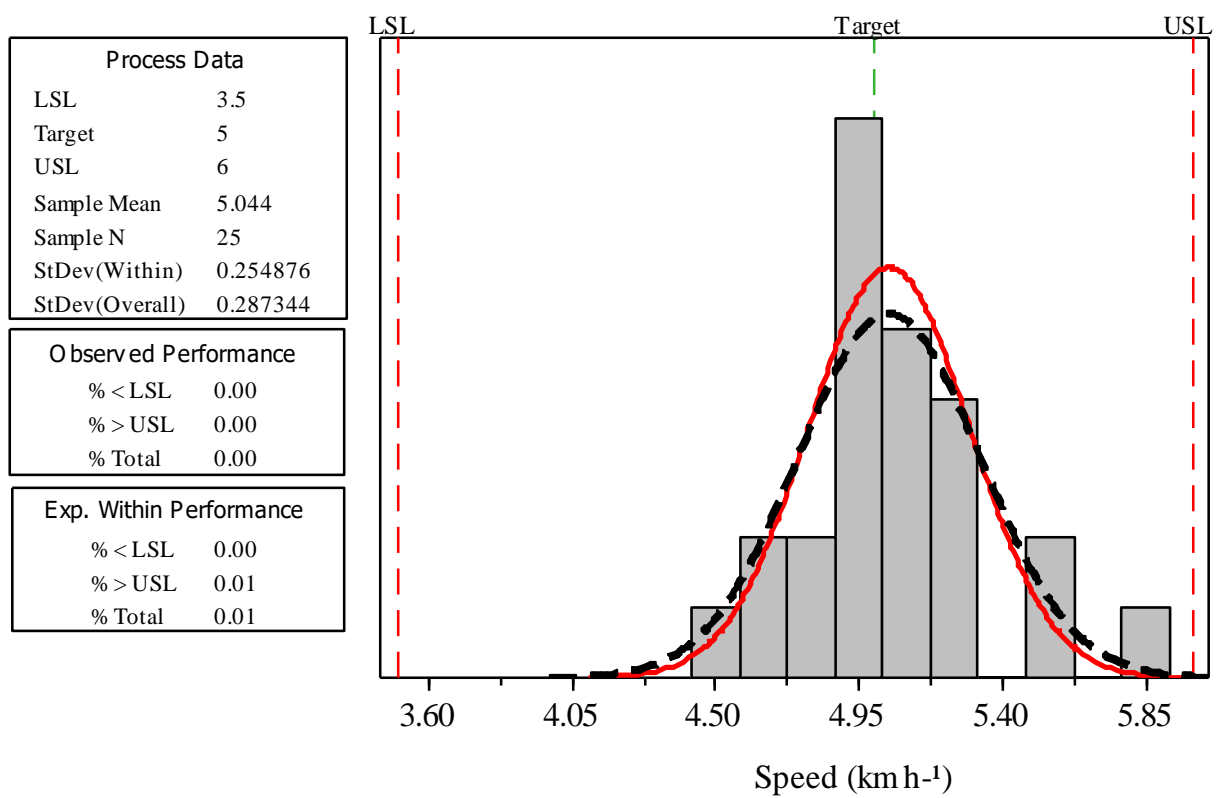

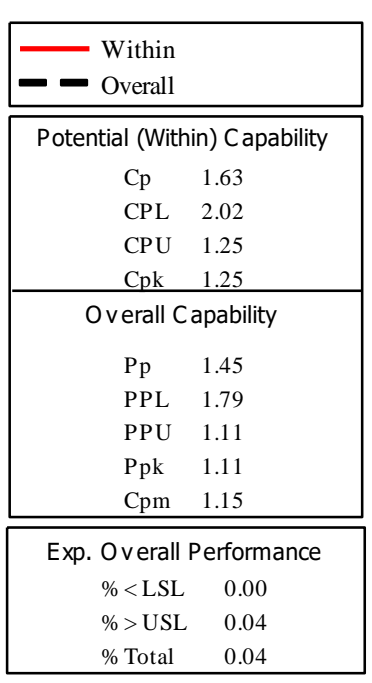

Speed $\left(\mathrm{kmh}^{-1}\right)$

FIGURE 7. Analysis of the process capability for the speed of the harvester in the trapezoidal plot during the soybean mechanized harvest.

Such comparison between the indexes $\mathrm{Cp}$ and $\mathrm{Cpk}$ and $\mathrm{Pp}$ and $\mathrm{Ppk}$ is fundamental because Cpk and Ppk alone cannot accurately represent the centering of the process, and if they were used when the standard deviation of the observations is minimal, the value Cpk and Ppk would be high, since they have an inversely proportional relation in their calculation basis, being isolated these values do not say anything about the average between the specifications (Montgomery, 2009).

Due to the current performance of the process, it was observed that there were no items or observations outside the specified limits (SUL and SLL), reflecting that $100 \%$ of the values meet the established limits. The analysis of the process potential performance shows that if there is the elimination of special causes and if is consider only the internal factors, only $0.01 \%$ of random causes will remain in the process, a situation in which the non-continuous monitoring of the process can be recommended to get rid of these variations.

By the analysis of the potential and general distribution curves it is verified that the process is not centered on the target ( $\mathrm{Cp}>\mathrm{Cpk}$ and $\mathrm{Pp}>\mathrm{Ppk}$ ), respectively. However, the $\mathrm{Cp}$ (1.47) and $\mathrm{Pp}$ (1.53) index are high and may represent a smaller variation between the specification limits (distribution with closer centralization of SUL rather than the target), and the association of these two factors determines that the process is able to meet the expected results, among the long-term specifications $(\mathrm{Pp}>1.33)$ and possibly short-term $(\mathrm{Cp}>1.33)$ for the engine rotation in the trapezoidal plot during soybean Mechanized harvest (Figure 8). 


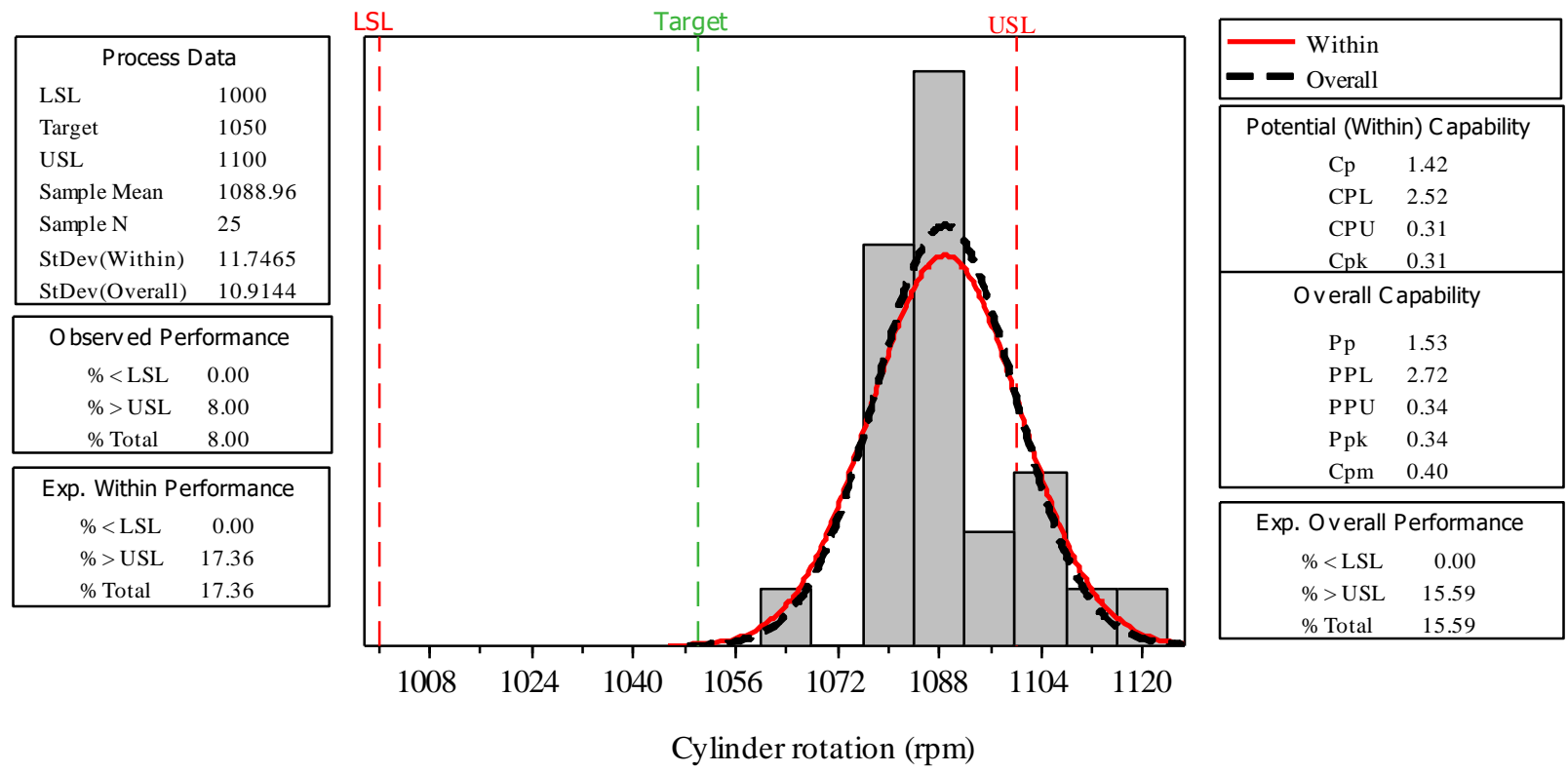

FIGURE 8. Analysis of the process capability for the cylinder rotation of the harvester in the trapezoidal plot during the soybean mechanized harvesting.

The general performance of the process produced $15.59 \%$ of the out-of-specification observations when intrinsic (random) and extrinsic (non-random) variations were considered for the calculation basis. The elimination of the source of external (non-random) variation to the process, that is, with presence of only random causes produces $17.36 \%$ of observations outside the specifications (above SUL). Therefore, for such situation it is not always advisable to eliminate the special causes by the complete analysis of the entire harvesting process, because when external variations are removed, remaining only the variability inherent to the operation, the quantity of items produced out of specifications increase smoothly.

Loureiro Júnior et al. (2014) evaluating the losses in soybean mechanized harvesting, reported that the cylinder rotation should remain above the quality levels established for the operation, and could be altered throughout the harvest to minimize losses and maximize the performance of the track performed by the harvester. This situation corroborates with the results of the present study, since the cylinder rotation is above the established quality standards, being the process able to remain satisfactory over a period of time.

\section{CONCLUSIONS}

The grain water contents affect the quality indicators of the performance on the soybean harvester in all the formats of the plots.

Working speed and cylinder rotation exhibit process stability throughout the soybean mechanized harvest.

The performance of the harvester was considered to be able to maintain between the specification limits and near the target within the sample collection time for the indicators of quality working speed for the irregular and trapezoidal plots and cylinder rotation for the trapezoidal plot.

\section{REFERENCES}

Aguila LSH, Aguila, JS, Theisen, G (2011) Perdas na colheita na cultura da soja. Pelotas, Embrapa, 1ed. p. 1-12.

Araldi PF, Schlosser GF, Frantz UG, Ribas RL, Santos PM (2013) Eficiência operacional na colheita mecanizada em lavouras de arroz irrigado. Ciência Rural 43(3):445-451. 
Cassia MT, Silva RP, Chioderoli CA, Noronha RHF, Santos EP (2013) Qualidade da colheita mecanizada de café em sistema de plantio circular. Ciência Rural 43(1):28-34.

Chioderoli CA, Silva RP, Noronha RHF, Cassia MT, Santos EP (2012) Perdas de grãos e distribuição de palha na colheita mecanizada de soja. Bragantia 71(1):112-121.

Compagnon AM, Silva RP, Cassia MT, Graat D, Voltarelli MA (2012) Comparação entre métodos de perdas na colheita mecanizada de soja. Scientia Agropecuaria 3(3):215-223.

Costa NP, Oliveira MCN, Henning AA, Krzyzanowski FC, Mesquita CM, Tavares LCV (1996) Efeito da colheita mecânica sobre a qualidade da semente da soja. Revista Brasileira de Sementes 18(2):232-237.

Custodio AAP, Silva RP, Lemos LB, Toledo A, Lima LP (2012) Controle estatístico aplicado na colheita mecanizada de cafeeiros irrigados. Revista de Agricultura 1:172-180.

Czarski A, Matusiewicz P (2012) Influence of measurement system quality on the evaluation of process capability index. Mettallurgy and Foundry Engineering 38(1):25-32.

Hunter JS (1989) A one point plot equivalent to the Shewhart chart with western electric rules. QualityProgress 2(1):13-19.

Hunter JS (1986) The exponentially weighted moving average. Journal of Quality Technology, Princeton 18:203-210.

Linhares M, Sette Júnior CR, Campos F, Yamaji FM (2012) Eficiência e desempenho operacional de máquinas. Pesquisa Agropecuária Tropical 42(2):212-219.

Loureiro Júnior AM, Silva RP, Cassia MT, Compagnon AM, Voltarelli MA (2014) Influence of the sample area in thev variability of losses in the mechanical harvesting of soybeans. Engenharia Agrícola 34(1):74-85.

Mesquita CM, Costa NP, Pereira JE, Maurina AC, Andrade JGM (2001) Caracterização da colheita mecanizada da soja no Paraná. Engenharia Agrícola 21(2):197-205.

Srivastava AK, Goering CE, Rohrbach RP, Buckmaster DR (1993) Engineering principles of agricultural machines. Michigan, ASAE, 2ed. p15-43.

Minitab (2007) Minitab Release 16: Meet Minitab 16. Minitab StatGuide; Minitab Help. [S.1.], Minitab.

Montgomery DC (2009) Control charts for variables. In: MONTGOMERY, D. C. Introduction to statistical quality control. Arizona, Wiley, 6ed. p226-268.

Silva RP, Cassia MT, Voltarelli MA, Compagnon AM, Furlani CEA (2013) Qualidade da colheita mecanizada de feijão (Phaseolusvulgaris) em dois sistemas de preparo do solo. Revista Ciência Agronômica 44(1):61-69.

Voltarelli MA, Silva RP, Zerbato C, Silva VFA, Cavichioli FA (2014) Agronomic capability of mechanized sugarcane planting. Australian Journal of Crop Science 8(10):1448-1460.

Voltarelli MA, Silva RP, Rosalen DL, Zerbato C, Cassia MT (2013) Qualityof performance of the operation of sugarcane mechanized planting in day and night shifts. Australian Journal of Crop Science 7(9):1396-1406.

Zerbato C, Furlani CEA, Voltarelli MA, Bertonha RS, Silva RP (2014) Quality control to seeding systems and densities in peanut crop. Australian Journal of Crop Science 8(6):992-998. 